\title{
LOCALIZATION AND ORGANIZATION OF RESPIRATORY NEURONS IN THE BRAIN-STEM OF THE TOAD, WITH REFERENCE TO ACTIVITIES OF SLOW MOTOR SYSTEM
}

\author{
Fumio Ito And Satoru WatANABE* \\ Department of Physiology, Nagoya University School of Medicine
}

The authors have investigated on the central nervous mechanism in the slow motor system (small-nerve motor system) of the toad, and found out spontaneous spike discharges in the brain-stem reticular formation which appeared often simultaneously with spontaneous slow responses in the forelimb muscles $^{9}$. During those observations, central discharges in regard to the respiratory action were frequintly recorded also from the reticular formation.

In many investigations on mammals, central respiratory discharges have so far been recorded mainly in the reticular formation of the medulla oblongata ${ }^{4,21)}$, and recently discharges from the supposed "pneumotaxic center" in the pons were also obtained ${ }^{228)}$. Few studies, however, on the respiratory center of frog or toad have been made, because their brains are very small, and their respiratory processes are more complicated. In general, the respiration of a frog is divided into two types, pulmonary and gorge respirations. According to the classification by PROSSER ${ }^{22}$ the former is regarded as a positive pressure type with ventilation of the lungs and the latter is a primitive one for gas exchange under lower metabolic states ${ }^{22}$

The gorge respiration has usually been considered to act for ventilation of the air in the gorge chamber, and was termed "ventilation respiration" (Ventilierende Atmung) by WEDENSKJI ${ }^{29)}$, who also suggested that the pulmonary respiration consisted of "swallowing respiration" (Einpumpende Atmung) and "disgorging respiration" (Entleerende Atmung). Recently, the types of respiration of a frog have been classified by $\mathrm{OKA}^{16)}$ into four categories; his type 1 , type 3 and type 4 may be corresponding to the ventilation, the swallowing and the disgorging respiration respectively, and the type 2 is one newly separated from the above three types as the basic and normal respiration, being attributed to lung ventilation. The normal pulmonary respiration of a toad has been studied electromyographically by SHINKAI and NARITA ${ }^{26)}$ who

Received for publication June 27, 1962.

* 伊藤文雄, 渡辺悟 
showed that the muscles participating respiratory movements should be divided into 3 groups rather than into 2, namely the expiratory and inspiratory groups. In the present experiment, the gorge and normal pulmonary respirations were defined according to OKA and SHINKAI, and the central nervous activities were investigated in comparison with activities of muscles investigated by them.

\section{METHODS}

An unanaesthetized toad was locked on a fixation plate. The skull was opened and the exposed brain was covered with liquid parafine. The electrode holder clamped on the head was described in the previous paper reported by the authors in regard to the central activities of the slow motor system $^{9}$.

Systematic exploration of the brain-stem was carried out with tungsten microelectrodes having a tip diameter of about $1 \mu$. The microelectrodes were inserted perpendicularly to the dorsal surface of the brain by means of a micromanipulator set on the electrode holding instrument, which functioned also as an indifferent lead. The position of the tip of the electrode was in each case approximated by the use of the micromanipulator. The exact localization of the structure generating respiratory volleys was determined topographically by the histological examination about the focus destroyed by the current flow through the microelectrode at the end of the experiments.

For electromyographical leading from respiratory muscles, $\mathrm{m}$. submaxillaris and $\mathrm{m}$. geniohyoideus were exclusively adopted, as it has been known that they act in both gorge and pulmonary respirations ${ }^{26)}$. The skin was removed from the submaxillar region, and silver wires insulated to their tips were inserted into the muscles. This bipolar method was convenient for simultaneous leading both responses of slow and fast muscles, as was in the experiments on the slow motor system ${ }^{9,10)}$.

In order to pick up the activities of the central neurons, a tungsten microelectrode was used, and connected with a cathode-follower amplifier. Action potentials of the muscles were amplified by $\mathrm{CR}$ preamplifier, having a time constant of $1.4 \mathrm{sec}$. These signals were displayed on a dual-beam cathode-ray oscilloscope, and also recorded on a three-element electromagnetic oscillograph, which was connected parallel with the former. The third element of the electromagnetic oscillograph was replaced with a pneumograph (a particular tambour mirror system), therefore the third trace was mechano-optical, not mediated electromagnetically. An injection needle having an inside diameter of $1.5 \mathrm{~mm}$ was stuck out through a nostril from the gorge cavity (mouth cavity), and was inserted into a vinyl tube of $15 \mathrm{~cm}$ length and $3 \mathrm{~mm}$ bore at one point near its closed end. The other end of the tube was connected with a tambour on which a mirror was pasted. This was used as the third element of the electromagnetic oscillograph. The amplitude of intra-gorge pressure could be augmented by closing the other nostril; however, the respiration tended to be abnormal in such condition, so that the nostril was left open.

In all the records, the positivity of the tip of microelectrode and positive pressure in the pneumograph were recorded as upward deflections. This experiment was performed during June-September.

\section{RESULTS}

\section{Gorge respiration.}

Intragorge pressure and muscle responses. The term "gorge respiration" in this report means a ventilation movement for exchanging intragorge air. 
In a condition with open nostril, the animals reduce the intragorge cavity by contraction of the submaxillar muscle groups, then the inspiration was done not only by relaxation of the muscles, but also by active contraction of $\mathrm{m}$. omohyoideus or $\mathrm{m}$. sternohyoideus, as was remarked by OKA ${ }^{16)}$. The intra-gorge pressure, however, showed a slow positive deflection of about $1 \mathrm{sec}$ in duration only in the expiratory phase, as was illustrated in FIG. 1, A.

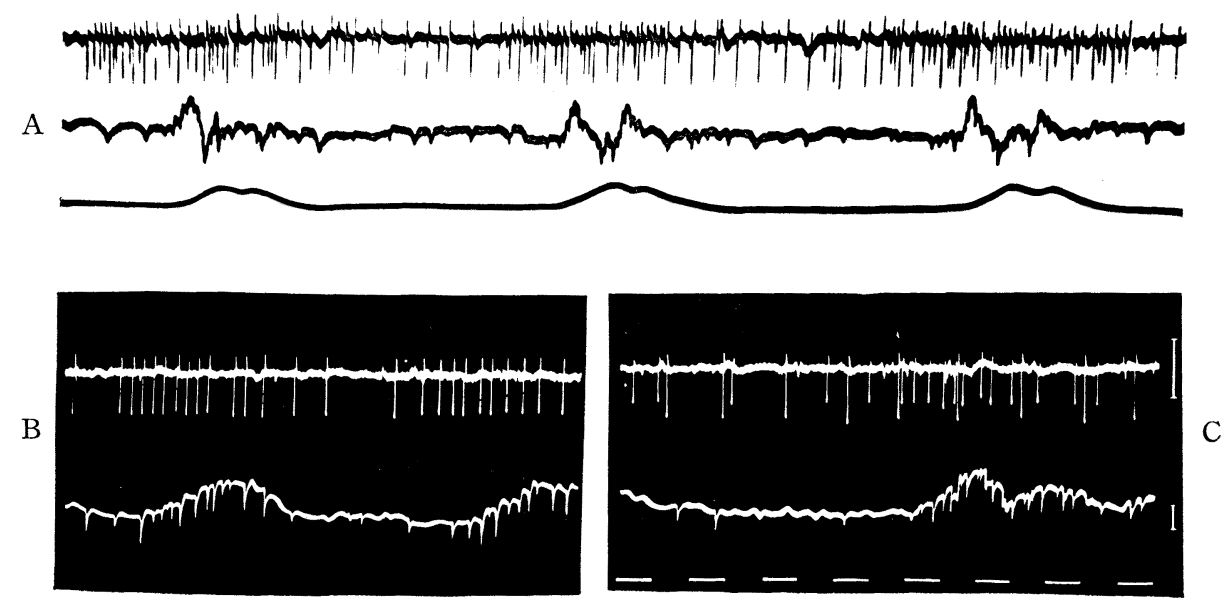

FIG. 1. Periodic discharges of the respiratory neurons in brain-stem with electromyograms of the submaxillar muscle, during the gorge respiration. Record A : activities recorded by electromagnetic oscillograph. Upper trace : neuron; middle trace: electromyogram; lower trace: intra-gorge pressure (positive pressure shown as upward deflection). B and C, cathode-ray oscillograms. C is overlapped by continuous discharges from the slow motor system. Vertical bar: $100 \mu \mathrm{V}$. Horizontal bar: $100 \mathrm{msec}$.

The electromyogram was characterized by successive discharges of only slow muscle response, without any fast muscle responses. The individual slow muscle potentials were about $100 \mu \mathrm{V}$ in amplitude, and their shape resembled that of spontaneous slow muscle potentials recorded from forelimb muscles as observed in our previous report ${ }^{9)}$. Slow responses of the submaxillar muscles were obtained rather regularly at about $7 / \mathrm{sec}$ in frequency even during the inactive phase of the gorge inspiration. The frequency increased transiently to about $20 / \mathrm{sec}$, preceding approximately $150 \mathrm{msec}$ to the rising of the intragorge pressure and the burst lasted for about $750 \mathrm{msec}$. These patterns of discharges were repeated with a period of about $3 \mathrm{sec}$, which may vary with the season and with the temperature. In most records, those slow muscle responses were often observed overlapped with much slower potential deflections which seemed to be yielded by mechanical vibration of the electrodes. The artifactual deflections could be reduced by restraining still the respiratory 
movement of the submaxillar muscles, but this procedure might induce some abnormal respirations or swallowing movements.

Localization of respiratory neurons. It has been well known that respiratory neurons in various vertebrates are scattered diffusely in the medulla oblongata and the mid-brain. By removal experiments on the frog brain, OkA ${ }^{17}$ ) has assumed that the normal respiratory centers are located in the regien between the optic lobes frontally and the obex caudally. Thus the systematic exploration of the brain-stem from the optic lobes to the obex was carried out in 14 toads. When the tungsten microelectrode was inserted about $1.2-1.5 \mathrm{~mm}$ into the brain near the margin of the floor of the fourth ventricle, at the level of the root of the vestibular nerve, a certain pattern of central firings corresponding to the gorge respiration was obtained, just prior to the deflection of the intragorge pressure and the responses of the submaxillar muscles. By a histological examination, the actual respiratory neurons were found to be located ventromedial to the vestibular nucleus and ventral to the facial nucleus, at the place which was named nucleus reticularis medius or reticular elements beside those nuclei by HERRICK ${ }^{7}$ and KAPPERs et al. ${ }^{22}$. In Fig. 2, A the points from
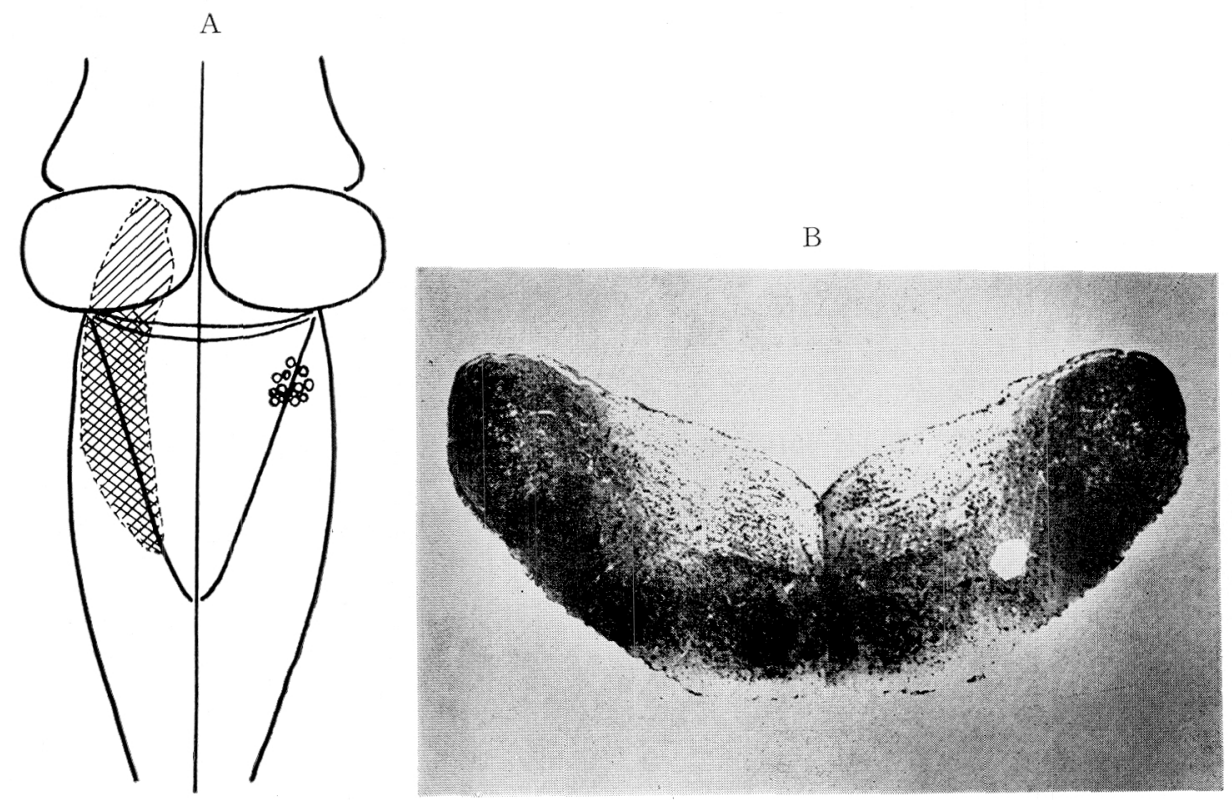

FIG. 2. The localizations of the large and small neurons. A was drawn on the basis of the data obtained from 14 toads of approximately same dimensions. Sites of gorge respiratory neurons observed in each case were indicated by an open circles. The area drawn by oblique lines yielded the pulmonary respiratory discharges, and the crosed area showed a normal respiratory center most generally observed. B shows a microphotograph of one histological section indicating the site of gorge respiratory neuron (a defect made by electrocoagulation). 
which gorge respiratory discharges were detected have been indicated by open circles at margin of the floor of the fourth ventricle. One example of the histological sections was depicted in FIG. 2, B.

Patterns of discharge. Respiratory discharges led extracellularly from the above mentioned central region were characterized by periodic bursts of low spike potentials as illustrated in FIG. 1. Each burst consisted of 12-20 spikes of about $100 \mu \mathrm{V}$, and the maximal frequency of discharges was at about 35/sec. Each started about $100 \mathrm{msec}$ prior to each initiation of the slow muscle responses, and continued for about $0.5 \mathrm{sec}$. The frequency of the discharges gradually decleased as the intragorge pressue declined, but the discharges did not disappear even in the pause of the gorge respiration. Actually, all the recordings throughout this study showed that there was no silent period between the activities of gorge respiratory neurons, although respiratory movements could usually be divided into expiratory, inspiratory and inactive phases. It may be considered that the neurons for the gorge expiration are always kept in a supraliminal state and the fluctuation in the excitability may give the alternation in the discharge frequency, in accordance with the respiratory movement. Low spike discharges mentioned above were recorded often overlapped with another type of rhythmic discharges at frequency of $3-5 / \mathrm{sec}$. The amplitude of the latter was about equal to that of the former or somewhat higher, so that they could not be differentiated from each other except by their patterns of discharge. The latter rhythmic ones must be identical with those due to central activity for the slow motor system that was reported in the previous paper". Considering from this result, the neurons for the gorge expiration may be situated in a close vicinity of the slow motor system.

\section{Pulmonary respiration.}

Intra-gorge pressure and muscle responses. The term "pulmonary respiration" is used here to mean a normal respiration defined by OKA ${ }^{16)}$. This respiration is composed of the initial rapid expiration, the closing of nostrils and the final swallowing movement of air into the lungs from the gorge cavity by contraction of submaxillar muscles. The initial expiration is done solely by coordinated movements of glosso-laryngeal muscles without contraction of breast and abdominal muscles ${ }^{13,16,26)}$, by which the intra-pulmonary air may be blown out through the gorge cavity. Therefore neither the intra-gorge pressure nor the electromyogram of the submaxillar muscles showed any characteristic deflection in this period. At the next stage, the nostrils are closed and the submaxillar muscles are contracted. These functional processes produced a prompt increase in the intra-gorge pressure, which was preceded by a short train of several volleys in the electromyographical record from the submaxillar muscles.' Individual muscular discharges in this burst were constituted only of slow muscle potentials of about $100 \mu \mathrm{V}$ in amplitude which seemed to be identical with the submaxillar slow muscle responses for the gorge respiration. The burst dis- 

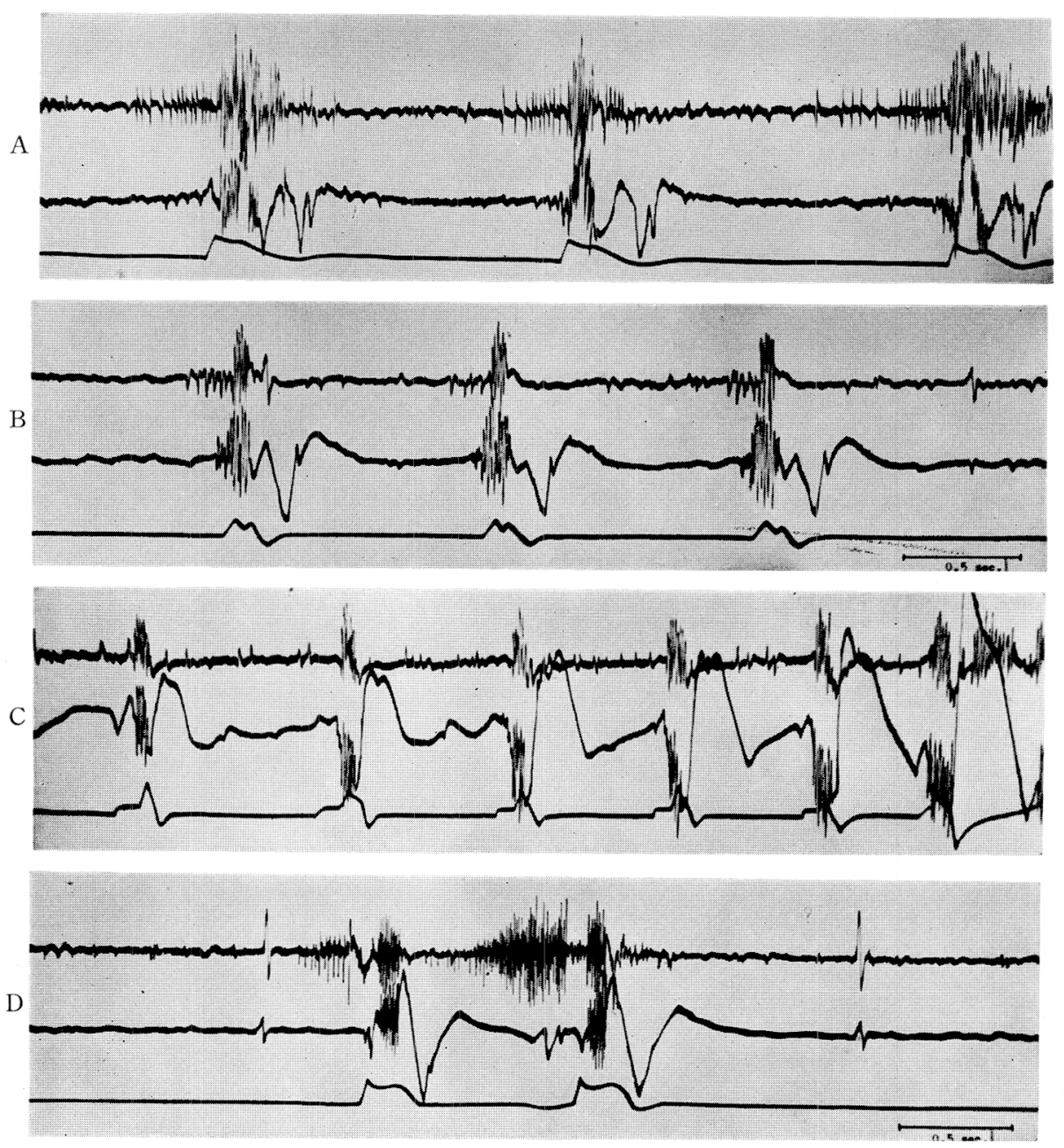

FIG. 3. Electromagnetic oscillograms during pulmonary respiration. In each set of three records, upper trace: neuron at firing; middle trace: electromyogram of submaxillar muscle; lower trace: intra-gorge pressure. A: neuronal actions were recorded from the site of gorge respiratory neurons. B: record at distance of about $3 \mathrm{~mm}$ caudal to the gorge respiratory center. $\mathrm{C}$ : gasping like respirations recorded from lobus opticus. D: one example of abnormal respirations caused by incision of the submaxillar muscle.

charges were composed of usually 4 to 8 spikes, i. e. higher than the frequency of slow muscle responses for the gorge respiration, as illustrated in FIG. 3.

Those transient gorge activities were immediately followed by the swallowing movement, in which the glosso-laryngeal muscles and sometimes even forelimb flexors synchronously contracted, then the hyoid cartilage was moved caudally and the intra-gorge air was driven into the lung. The intra-gorge 
pressure was decreased in this period, and the intra-pulmonary pressure might well have been increased. The electromyogram simultaneously recorded from the submaxillar muscle showed a vigorous burst of fast muscle responses (twitch muscle discharges) which were incompletely synchronized and reached about $1 \mathrm{mV}$ in its maximum amplitude. Since the submaxillar muscle has been demonstrated by YOSHIDA ${ }^{31)}$ to be composed of slow and fast muscle fibres, the muscle should be able to show both responses, though scattered potentials from adjacent (deeper) muscles also must be considered. These bursts of fast discharges continued for approximately $100 \mathrm{msec}$, and were followed by very slow potential deflections which are due to artifactual vibration caused by contraction of the submaxillar muscles.

Localization and discharge patterns of neurons. As mentioned above, the swallowing movement was always preceded by the transient gorge respiratory action. As stated in the preceding chapter, the neurons for the gorge respiration were localized in a limited portion adjacent to the vestibular nucleus.

First, when central activities of the pulmonary respiration were led with the tungsten electrode laid in or about the centrum for the gorge respiration, several trains of low spike discharges like those observed during gorge respiration appeared, were always followed by a characteristic large spike burst of the swallowing respiration. In most cases, the low spike potentials were about $100 \mu \mathrm{V}$ in amplitude and discharged at about $85 / \mathrm{sec}$ in frequency. The duration of the burst was $50-80 \mathrm{msec}$, in which 4 to 10 spikes were included, as illustrated in FIG. 4. The durations and numbers of those discharges were markedly varied with the location of the electrode. On the other hand, the large spike burst started following a silent period of about $30 \mathrm{msec}$ after the cessation of the low spike discharges. Individual spike potentials were in the range of 150 to $200 \mu \mathrm{V}$, but compound large potentials incompletely synchronized with each other were found to be of around $300 \mu \mathrm{V}$. These central spike discharges started about $10 \mathrm{msec}$ before the appearance of fast muscle responses, and the discharges continued for about $100 \mathrm{msec}$ which was equal to the duration of fast muscle responses. The fact that the amplitude of the central discharges for the swallowing is larger than that for the ventilation seems to indicate that the size of central neurons for the swallowing movement may be somewhat larger than that for the ventilation movement. It is concluded that the transient discharges of small respiratory neurons which belong to the slow motoneuron occur at first in the pulmonary respiration, and when their activities are transmitted synaptically to the adjacent large respiratory neurons which belong to the fast motoneuron, the swallowing movement is provoked.

Next, when extensive areas from the mid-brain to the caudal segment of medulla oblongata outside the center for the gorge respiration were explored, the foregoing low spike bursts were either lowered and somewhat deformed or disappeared completely as shown in FIG. 3. The following large spike bursts, 


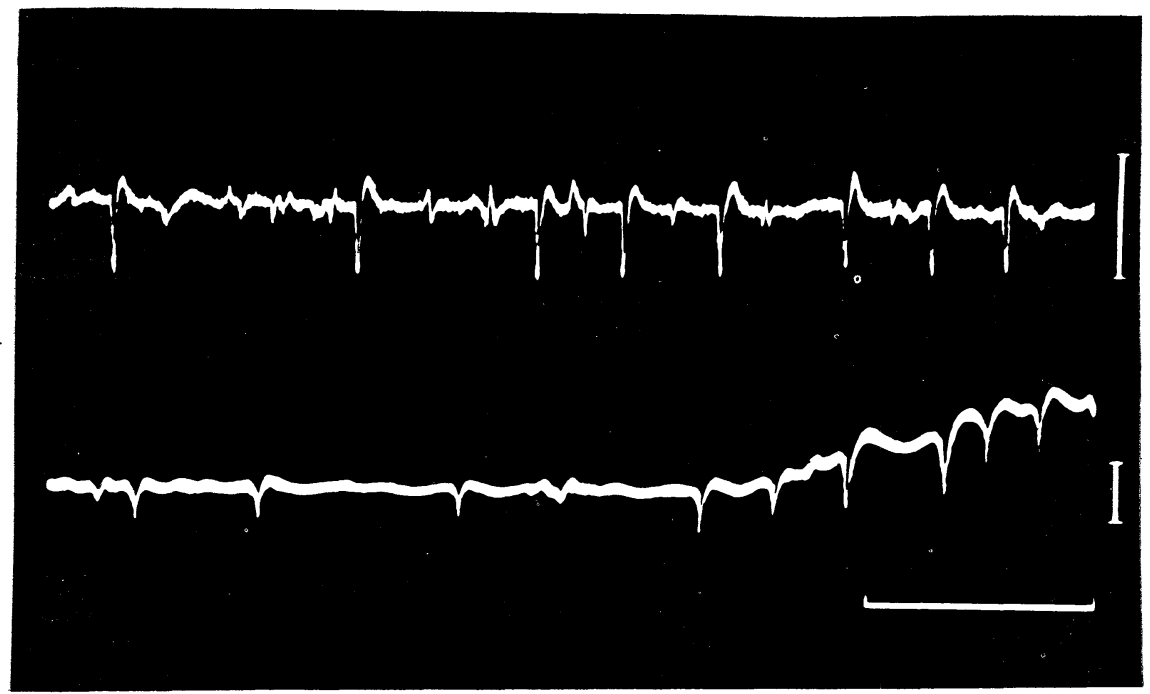

A

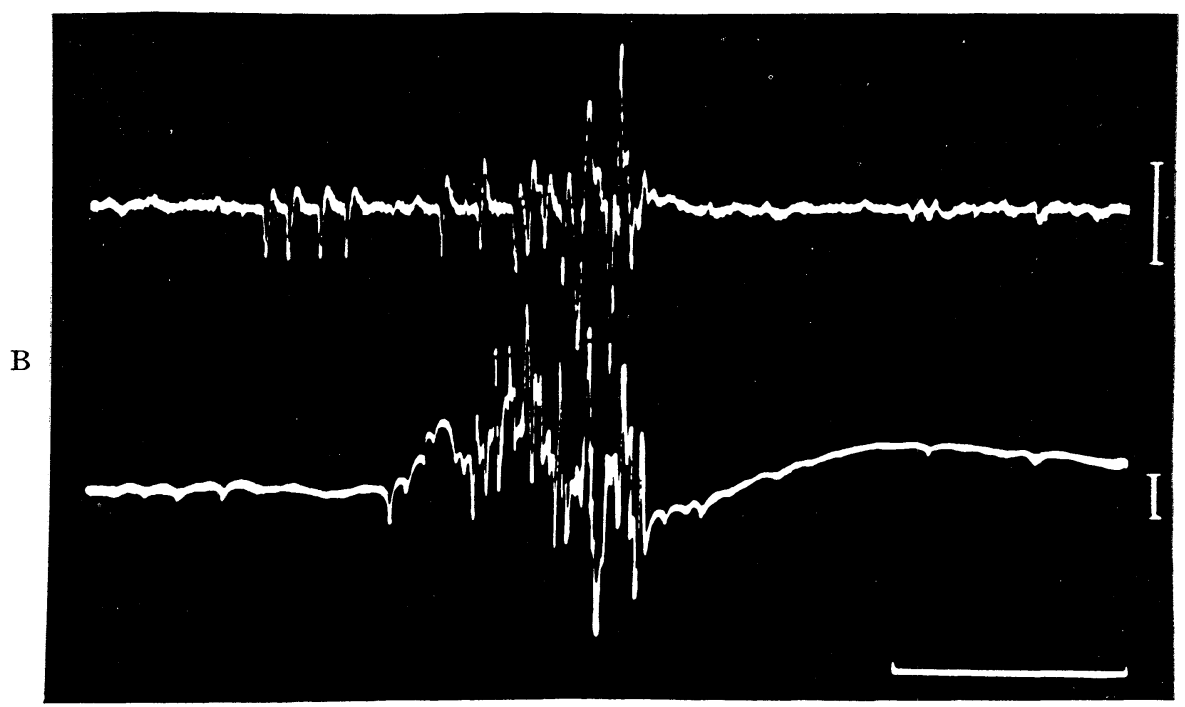

FIG. 4. High speéd tracings of typical discharges during gorge respiration (A) and pulmonary respiration (B). In each pair of records, upper trace : respiratory neuron actions led from the gorge respiratory center; lower trace : electromyogram. Vertical bar: $100 \mu \mathrm{V}$. Horizontal bar : $100 \mathrm{msec}$.

however, could be obtained from throughout the extended area as was drawn with oblique lines in FIG. 2, A. On detailed observation, the initiation of the large spike bursts seemed to be delayed in proportion to the distance between the electrode and the site of gorge respiratory neurons. The time delay may be considered to indicate the time for irradiation of respiratory excitations dis- 
persed along the synaptic relays of respiratory neurons. The dispersing velocity of the irradiation might be calculated from the time differences between initiations of the bursts recorded from different portions of the brain. For convenience, the onset of the fast muscle response recorded in parallel with the central nervous activities was taken as the zero-point for calculation, and the time intervals between the onset and the initiation of central large spike discharges were measured. The large spike bursts obtained from a rostral portion of the medulla oblongata, which lies $3 \mathrm{~mm}$ caudal to the gorge respiratory center, started just at the same time as the onset of fast muscle responses or slightly delayed. Since the large spike bursts recorded from the site of the gorge respiratory neurons started approximately $10 \mathrm{msec}$ before the onset of the fast responses as indicated above, time delay should be about $10-12 \mathrm{msec}$, hence the irradiation velocity was calculated as $0.3-0.25 \mathrm{~m} / \mathrm{sec}$ at $25^{\circ} \mathrm{C}$.

Under some conditions difficult to perform the swallowing movement, for example when the intra-gorge pressure could not be raised sufficiently because of damaged nostril canal or of injury of submaxillar muscles, various types of abnormal swallowing movements were seen; electrographic records showed tremendous large spike discharges in the brain and vigorous and fast (twitch) responses in the muscle, as illustrated in FIG. 3, D. Besides, the central large spike discharges were obtained from further extended areas including parts of the diencephalon and even of the telencephalon. In those records, measurable time intervals between the initiation of the large spike burst and onset of fast muscle responses may greatly be shortened in comparing with the normal respiration. For instance, when a point about $8 \mathrm{~mm}$ frontal to the gorge respiratory center was sampled with microelectrodes, the initiation of the large spike bursts was delayed about $30 \mathrm{msec}$ from the onset of fast muscle responses. Hence, the irradiation velocity was calculated as $0.2 \mathrm{~m} / \mathrm{sec}$.

\section{DISCUSSION}

The location and the activity of neurons for normal (pulmonary) respiration in frogs have been investigated by means of microelectrodes and local removal of the brain ${ }^{16,17)}$, but not hitherto those of gorge respiratory neurons are definitely known. The present study reveals that a few neurons in regard to the gorge respiration lie underneath the striae acousticae. The location of respiratory neurons is in substantial agreement with that asserted by OKA ${ }^{18)}$, but the authors cannot subscribe to his opinion assuming that the neurons located in this area are for the pulmonary respiration. It was found out in the present experiment that the region was occupied by neurons for the gorge ventilation movement, and that neurons for the pulmonary respiration are scattered in the somewhat lateral part of the medullary reticular system from the caudal portion of optic lobe to the obex. It might well be considered that the site 
of the gorge respiratory neurons is coincided with the origin of irradiation of the pulmonary respiratory actions, and therefore, the "typical central response" for the pulmonary respiration was recorded from the site of the gorge respiratory neurons. Activities of gorge respiratory neurons can be definitely differentiated from those of the pulmonary respiratory neurons, especially owing to the pattern of the former, that is characterized by continuous rhythmic discharges of low spike potentials, and that it resembles the neuronal discharges of slow motor system situated in the reticular formation in their immediate vicinity ${ }^{9}$. A close relationship between both neurons of the gorge respiration and of the slow motor system may also be supported further by the distinct evidence that activities of the gorge respiratory neurons always caused slow muscle responses in the submaxillar muscle.

Although a regular fluctuation in the frequency of these low spike discharges was observed during the gorge respiration, there was no silent period. Recently, Salmoiraghi and Delisle Burns ${ }^{23)}$ demonstrated that the inspiratory and expiratory neurons in the medulla of a cat fired continuously with lower frequencies during their inactive phases. They stated that the discharges of respiratory neurons were maintained by a self-reexcitation process within the networks of inspiratory or expiratory neurons ${ }^{24,25}$.

During a cycle of the pulmonary respiration, continuous discharges of low spike potentials disappeared, and a peculiar large spike burst took place, always preceded by a short train of several low spikes. This fact seems likely to indicate that the small neurons for the gorge respiration always act as the igniter of the pulmonary respiration. Thus, it might be explained that the gorge respiration is maintained by continuous discharges of basal neurons less than about $35 / \mathrm{sec}$ in frequency, whereas a transient burst of the small (basal) neurons of about $85 / \mathrm{sec}$ facilitates a transmission to the large neurons, which drives the pulmonary respiration. This explanation may support the hypothesis that the respiratory rhythm is dictated by the activity of certain pacemaker neurons endowed with a property of spontaneous discharges ${ }^{1,3,8,30)}$. This spontaneous activity of the pacemaker neurons may be considered also to be maintained by a self-reexcitation process. As was stated above, the present experiment was made electromyographically on m. submaxillaris. This muscle causes mainly compression of the intra-gorge pressure, but does not large participate in the swallowing movement of the pulmonary respiration, which may be rather contributed by the glossopharyngeal muscles, e. g. m. sternohyoideus and $\mathrm{m}$. geniohyoideus. Submaxillar muscle are innervated by r. mandibularis of the facial nerve, while the glossopharyngeal muscles by $n$. hypoglossus in the 2nd spinal nerve. It is interesting that the facial nerve contains more slow motor fibres and less fast motor fibres than the 2nd spinal nerve. ITO and his co-workers ${ }^{11}$ made a similar observation in the study of distribution of both motor systems in the spinal cord. 


\section{SUMMARY}

The brain stem of toads was explored with a tungsten microelectrode in order to locate the somata of respiratory neurons, with a simultaneous application of electro-myography to the submaxillar muscle.

1. Small respiratory neurons for the gorge respiration were located in a limited region underneath the striae acousticae. The region is near the margin of the floor of the fourth ventricle at the level of the root of the vestibular nerve and at the depth of about $1.2-1.5 \mathrm{~mm}$ from the dorsal surface of the brain.

2. Their activity was characterized by continuous discharges of low spikes of about $100 \mu \mathrm{V}$ in amplitude with fluctuating intervals, by which the ventilation movement of the submaxillar muscle was put to action.

3. During the ventilation movement (gorge respiration), slow muscle responses were exclusively recorded from the submaxillar muscles. Therefore the small neurons which caused the responses were assumed to belong to the slow motor system.

4. Large neurons for pulmonary respiration were found more extensively around the region of the small neurons, reaching the optic lobe frontally and the obex caudally.

5. Large spike bursts of about $300 \mu \mathrm{V}$ in amplitude due to activities of the large neurons were always preceded by several low spike discharges of about $85 / \mathrm{sec}$ in frequency, which seems to be caused by an increased excitability of the small neurons. Then twitch (fast) responses occurred in the submaxillar muscles, always preceded by a short train of high frequent slow muscle responses.

6. Activities of their large neurons were measured to irradiate at about 0.2 to $0.25 \mathrm{~m} / \mathrm{sec}$ along synapic relays between them.

The authors wish to express their gratitude to Prof. R. ITo for his continued guidance throughout this work.

\section{REFERENCES}

1) Adrian, E.D. and Buytende jk, F.J.J. Potential changes in the isolated brainstem of the goldfish. J. Physiol. 71: 121-135, 1931.

2) Breckenridge, C. G. and Hoff, C. E. Pontine and medullary regulation of respiration in the cat. Amer. J. Physiol. 160:385-394, 1950.

3) Gesell, R. A neurophysiological interpretation of the respiratory act. Ergebn. Physiol. 43 : 477-639, 1940.

4) Gesell, R., Bricker, J. and Magee, C. Structural and functional organization of the central mechanism controlling breathing. Amer. J. Physiol. 117: 423-453, 1936.

5) Gesell, R. and Moyer, C. The dual excitatory action of the vagal stretch reflex. Amer. J. Physiol. 131 : 674-680, 1940-41.

6) Gesell, R. and Worzniak, J. J. On the origin of the expiratory activity patterns. 
Amer. J. Physiol. 131 : 681-686, 1940-41.

7) Herrick, C. J. The medulla oblongata of necturus. J. Comp. Neurot. 50: 1-96, 1930.

8) Hukuhara, T. and OKada, H. On the automaticity of the respiratory centers of the catfish and crucian carp. Jap. J. Physiol. 6: 313-320, 1956.

9) Ito, F. and Watanabe, S. Spontaneous activity of the central nervous in the toad's small-nerve motor system. Jap. J. Physiol. $11: 1-12,1961$.

10) Iто, F. Slow muscle responses induced by the stimulation of the brain-stem reticular formation. Jap. J. Physiol. $11: 289-303,1961$.

11) Iто, F., Iто, R. unpublished.

12) Kappers, C. U. A., Huber, G. C. and Crosby, E. C. The comparative anatomy of the nervous system of vertebrates, including man. Macmillan C. Newyork. 1936. Vol. I. p. 653.

13) Kato, H. Studies on normal respiration of frog. Part I. Normal respiration and $\mathrm{CO}_{2}$-effect on it. (Japanese) J. Physiol. Soc. Jap. 13:319-322, 1951.

14) Lumsden, T. Observations on the respiratory centers in the cat. J. Physiol. 57 : 153-160, 1923.

15) Marckwald, M. Die Atem Bewegungen und deren Innervation beim Kaninchen. Z. Biol. $23: 149-263,1887$.

16) OKa, K. The normal respiratory movements of the frog. (Japanese) J. Physiol. Soc. Jap. 19: 613-620, 1957.

17) OKA, K. The influence of the transection of the brain upon the respiratory movement of the frog. (Japanese) J. Physiol. Soc. Jap. 20:513-519, 1958.

18) OKA, K. Further studies on the localization of the respiratory centers of the frog. (Japanese) J. Physiol. Soc. Jap. $20: 520-524,1958$.

19) Pitts, R.F. Interrelations of the respiratory centers in the cat. Amer. J. Physiol. 126 : 689-707, 1939.

20) Pitts, R.F. Organization of the respiratory center. Physiol. Review. 26: 609-630, 1946.

21) Pitts, R.F., Magoln, H. W. and Ranson, S. W Localization of the medullary respiratory centers in the cat. Amer. J. Physiol. 126:673-688, 1939.

22) Prosser, C. L. Comparative animal physiology. Saunders C. Philadelphia. 1952. p. 220 .

23) Salmoiraghi, G. C. and Delisle Burns, B. Localization and patterns of discharge of respiratory neurons in brain-stem of cat. J. Neurophysiol. 23:2-13, 1960.

24) Salmoiraghi, G. C. and Delisle Burns, B. Notes on mechanism of rhythmic respiration. ibid. $23: 14-26,1960$.

25) Salmoiraghi, G. C. and Delisle Burns, B. Repetitive firing of respiratory neurons during their burst activity. ibid. $23: 27-46,1960$.

26) ShinkAi, K. and NARITA, T. Electromyographical studies on toad's respiratory movements. Nagoya J. Med. Scie. 19: 1-6, 1957.

27) TAKAGI, K. Regulation of the respiration. Recent advance of physiology. (Japanese) Nanjo C. Tokyo. 127-197, 1949.

28) TAkagi, K. and Nakayama, T. Respiratory discharges of the pons. Science. 128 : 1206, 1958.

29) Wedenskji, N. Über die Atmung des Frosches. Pflügers Arch. Physiol. 25: 129, 1881.

30) Winterstein, N. H. Die automatische Tätigkeit der Atemzentren. Pfïgers Arch. Physiol. 138 : 159-166, 1911.

31) Yoshida, Y. Electrophysiological studies on two kinds of skeletal muscle fibers of the toad's geniohyoideus muscle. (Japanese) J. Physiol. Soc. Jap. 20:129-142, 1958. 